\title{
Thermodynamic Analysis of a Gas Turbine Power Plant Modeled with an Evaporative Cooler
}

\author{
${ }^{1}$ S. O. Oyedepo* and ${ }^{2}$ O. Kilanko \\ ${ }^{1,2}$ Mechanical Engineering Department, Covenant University, Ota, Nigeria \\ e-mail: Sunday.oyedepo@covenantuniversity.edu.ng
}

\begin{abstract}
In this paper the performance enhancement of gas turbine power plants by cooling the compressor intake air with an evaporative cooler is studied. This study investigated the effect of inlet air cooling system on the performance of an existing gas turbine power plant in Nigeria. The results show that for each $5^{\circ} \mathrm{C}$ decrease of inlet air temperature, net output power increases around 5-10\% and the thermal efficiency increases around 2-5\%. It is shown that the amount of this increase is higher when the pressure ratio is high and turbine inlet temperature is low. The results of this study shows that retrofitting of the existing gas turbine plant with inlet air cooling system gives a better system performance and may prove to be an attractive investment opportunity to the Nigeria government and stakeholders of the plant.
\end{abstract}

Keywords: Gas turbine plant performance; relative humidity; dry bulb temperature; ambient temperature; turbine inlet temperature.

\section{Introduction}

The gas turbines are widely being used for producing electricity, operating airplanes and for various industrial applications such as refineries and petrochemical plants [1]. In aircraft propulsion or drives for vehicles, gas turbines are chosen due to their large power-to-weight and power-tovolume ratio. Furthermore, for certain operating conditions the cycle efficiency of gas turbines is high compared to piston engines. In the field of energy generation, gas turbines have often been chosen in the past when fast start and shut down on demand is required. This is especially needed for compensating peak loads over the daytime. In contrast, steam cycles as used for coal and oil firing or nuclear power are base-load machines since the start and shut down is tremendously longer due to the large heat capacity in the cycle [2].

The basic gas-turbine cycle has low thermal efficiency, so it is important to look for improved gas turbine based cycles [1]. Therefore, enhancing the performance of Gas turbine was successful through raising the turbine inlet temperature (TIT) and the compressor pressure ratio and advances in cooling technology and material science caused high turbine inlet temperature conceivable [3].

Gas turbines (GTs) have been used for electricity generation in most countries around the world. In the past, their use has been generally limited to generating electricity in periods of peak electricity demand. Gas turbines are ideal for this application as they can be started and stopped quickly enabling them to be brought into service as required to meet energy demand peaks [4]. However, due to availability of natural gas at relatively cheap prices compared to distillate fuels, many countries around the world, e.g. Nigeria, use large conventional GTs as base load units, while small ones to meet any shortages in available electricity supplies occurring during an emergency or during the peak load demand periods. Such systems, especially those operating in an open or simple cycle have the disadvantage of being least efficient and so the unit cost of generated electricity is relatively high.

The average efficiency of gas turbine plants in the Nigerian energy utility sector over the past three decades was in the range $27-30 \%$ [5]. The low efficiencies of the gas turbine plants are tied to many factors which include: operation mode, poor maintenance procedures, age of plant, discrepancies in operating data, high ambient temperature and relative humidity.

Thermodynamic analyses exposed that thermal efficiency and specific output decrease with an increase of humidity and ambient temperature as shown by FarzanehGord and Deymi-Dashteba [6]. Bird and Grabe [7] have studied the effect of humidity on gas turbine performance and formulated correlations. El-Hadik [8] carried out a parametric study on the effects of ambient temperature, pressure, humidity and turbine inlet-temperature on power and thermal efficiency. He concluded that the ambient temperature has the greatest effect on gas turbine performance, which increases with the turbine inlettemperature and pressure ratio. Reductions of power and efficiency due to a $1 \mathrm{~K}$ temperature growth were found to be around $0.6 \%$ and $0.18 \%$, respectively. The work of Ibrahim et al. [9] also shows that an increment of $1{ }^{\circ} \mathrm{C}$ in the compressor air inlet temperature decreases the gas turbine power output by $1 \%$. These serve as evidence that gas turbine performance is sensitive to the ambient air temperature. As the ambient air temperature rises, less air can be compressed by the compressor since the swallowing capacity of compressor is given, and then the gas turbine output is reduced at a given turbine entry temperature. In addition, the compression work increases because the specific volume of the air increases in proportion to the intake air temperature [10]. Generally speaking, the gas turbine is designed to operate with a constant air volume flow in the compressor. When the ambient air temperature increases, its specific mass is reduced, so that the mass flow 
rate entering the turbine is accordingly decreased. This would, in turn, decrease the power output of the gas turbine. Strictly speaking, the power output is directly dependent on the mass flow rate of the air in the cycle. For each degree Celsius increase of the air temperature, $0.5-0.9 \%$ of the power output of the gas turbine cycle is reduced [11]. The efficiency and power output of a gas turbine during hot conditions is less than power output during cold conditions. The performance of the plant efficiency is decreasing as the ambient temperature increases, due to the inverse relation between air density and temperature. Cooling the inlet air of gas turbine, decreases the temperature which increases the air density, hence increasing the mass flow rate.

Many researchers have studied different cooling methods to enhance the performance of GT plants operating at high conditions of ambient temperature [12, 13, 14]. Johnson [15] presented a discussion of the theory and operation of evaporative coolers for industrial gas turbine installations. Calculations of parameters to predict the performance of evaporative cooler were discussed, in addition to installation, operation, feed water quality and the causes and prevention of water carry-over. Ondryas et al [16] investigated the impact of using chillers at the air intake to boost gas turbines power in cogeneration plants during high ambient temperatures. Three types of chillers i.e, absorption, vapour-compression and thermal energy storage were studied.

Johnke and Mast [17] reported that a media cooler can increase the relative humidity of the inlet air to about $90 \%$, thus increasing the power output by $5-10 \%$ and the efficiency by $1.5-2.5 \%$. Ameri and Hejazi [18] have carried out feasibility of installing an absorption chiller system to cool the inlet air to the Chabahar power plant gas turbines. It has been shown that the average power output can be increased by as much as $11.3 \%$. Kakaras et al. [19] have presented a computer simulation of the integration of an innovative absorption chiller technology for reducing the intake-air temperature in gas turbine plants. They concluded that the effect of ambient air temperature variation has the large penalty in the plant's performance for high ambient temperatures.

Abam et al [14] carried out performance analysis and components irreversibilities of a $25 \mathrm{MW}$ gas turbine power plant modeled with a spray cooler. The results obtained show that the use of a spray cooler on the existing gas turbine cycle gives a better thermal efficiency and less irreversibility rate in the components system and the entire plant. The power output of the gas turbine plant with spray cooler was found to have increased by over $7 \%$, accompanied by $2.7 \%$ increase in machine efficiency with a reduction in specific fuel consumption of 2.05 and $10.03 \%$ increase in the energy of exhaust.

Considering the rapid increase in electricity demand in Nigeria and the expected shortages in power supply due to delays in implementation of the major power projects, retrofitting the existing Gas Turbine (GT) power plants in the power sector with inlet-air cooling system is an attractive investment opportunity for the Power Holding Company of Nigeria (PHCN). It is the aim of this study to model an active 33.5 MW barge gas turbine plant with an evaporative cooler. Also, the study investigates the performance enhancement and modification of a gridconnected gas turbine plant operating at Egbin Power Station in Nigeria using the prevailing climatic conditions. The performance of the proposed modified Brayton cycle is compared with base case condition (without inlet air cooling).

\section{Materials and Methods \\ 2.1 Data Collection}

Operating data for a gas turbine unit were collected from the daily turbine control log sheet for a period of five years (2006-2010). The daily average operating variables were statistically analyzed and mean values were computed for the period of January to December, followed by an overall average. A summary of the operating parameters of the PB204 unit used for this study is presented in Table 1.The analysis of the plant was divided into different control volumes and performance of the plant was estimated using component-wise modeling. Mass and energy conservation laws were applied to each component and the performance of the plant was determined for the simple system (without evaporative cooler) and for the cooled system (with evaporative cooler).

Table 1: Summary of operating data for the 33.5-MW barge gas turbine power plant

\begin{tabular}{|l|l|l|l|}
\hline $\mathrm{S} / \mathrm{N}$ & \multicolumn{1}{|c|}{ Operating Parameters } & \multicolumn{1}{c|}{ Value } & \multicolumn{1}{c|}{ Unit } \\
\hline 1 & $\begin{array}{l}\text { Mass flow rate of air through } \\
\text { compressor }\left(\mathrm{m}_{\mathrm{a}}\right)\end{array}$ & 125.2 & $\mathrm{~kg} / \mathrm{s}$ \\
\hline 2 & $\begin{array}{l}\text { Temperature of inlet air to compressor } \\
\left(\mathrm{T}_{1}\right)\end{array}$ & 304 & ${ }^{\circ} \mathrm{K}$ \\
\hline 3 & Pressure of inlet air to compressor $\left(\mathrm{P}_{1}\right)$ & 0.1013 & $\mathrm{MPa}$ \\
\hline 4 & $\begin{array}{l}\text { Outlet temperature of air from } \\
\text { compressor }\left(\mathrm{T}_{2}\right)\end{array}$ & 622 & ${ }^{\circ} \mathrm{K}$ \\
\hline 5 & $\begin{array}{l}\text { Outlet pressure of air from compressor } \\
\left(\mathrm{P}_{2}\right)\end{array}$ & 0.980 & $\mathrm{MPa}$ \\
\hline 6 & Fuel-gas(natural gas) mass flow rate $\left(\mathrm{m}_{\mathrm{f}}\right)$ & 4.5 & $\mathrm{~kg} / \mathrm{s}$ \\
\hline 7 & Fuel- air ratio at full load $($ on mass basis) & 0.036 & - \\
\hline 8 & Inlet pressure of fuel-gas & 1.2 & $\mathrm{MPa}$ \\
\hline 9 & Inlet temperature to gas turbine $\left(\mathrm{T}_{3}\right)$ & 1219 & ${ }^{\circ} \mathrm{K}$ \\
\hline 10 & Turbine outlet gas temperature & 750 & ${ }^{\circ} \mathrm{K}$ \\
\hline 11 & Exhaust gas temperature & 715 & ${ }^{\circ} \mathrm{K}$ \\
\hline 12 & Lower Heating Value $(\mathrm{LHV})$ & $47,541.6$ & $\mathrm{~kJ} / \mathrm{kg}$ \\
\hline 13 & Isentropic efficiency of Compressor & 85 & $\%$ \\
\hline 14 & Isentropic efficiency of Turbine & 87 & $\%$ \\
\hline 15 & Combustion efficiency & 99 & $\%$ \\
\hline
\end{tabular}

\subsection{Thermodynamic Model of Gas Turbine Unit (Simple type)}

Figure 1 shows the schematic diagram of the single shaft gas turbine cycle selected in this study. The compressor inlet temperature is equal to ambient temperature in the base-case which neglects the cooling effect and simulates the cycle under ISO conditions $\left(\mathrm{T}_{0}=\right.$ $15{ }^{\circ} \mathrm{C}, \mathrm{P}_{0}=101.3 \mathrm{kPa}$ and $\phi=60 \%$ ) and without pressure drop at inlet and exhaust ducts. Thus, the inlet pressure is given by Ewa et al [20]:

$P_{0}=P_{03}$

The air and combustion products are assumed to behave as ideal gases.

The pressure of the air leaving the compressor $\left(\mathrm{P}_{04}\right)$ is calculated as:

$P_{04}=r . P_{03}$

where $r$ is the compression ratio. 


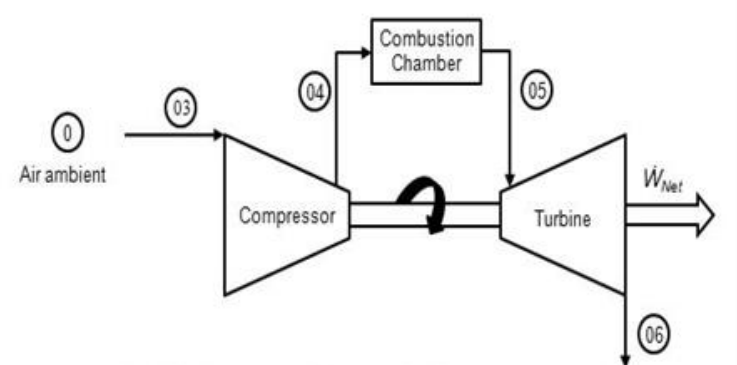

Figure 1 Schematic of the standard gas turbine cycle.

Assuming an ideal gas for state 04 and taking the isentropic efficiency of compressor to be 0.85 , the total temperature of the fluid leaving the compressor can be evaluated using ideal gas relations

$T_{04}=\frac{T_{03}}{\eta_{c}}\left[\left(\frac{P_{04}}{P_{03}}\right)^{\frac{\gamma-1}{\gamma}}-1\right]+T_{03}$

where $\eta_{c}$ is the compressor efficiency and $\gamma$ is the specific heat ratio.

The compressor work is calculated from the mass flow rate and enthalpy change across the compressor as follows:

$\dot{W}_{c}=\dot{m}_{a} C_{p a}\left(T_{04}-T_{03}\right)$

where $\dot{m}_{a}$ is the air mass flow rate and $C_{p a}$ is the specific heat capacity of air which is considered in this study as a temperature variable function and can be fitted by Equation (5) for the range of $200 \mathrm{~K}<\mathrm{T}<800 \mathrm{~K}$ [11]:

$c_{p a}(T)=1.04841-\left(\frac{3.8371 T}{10^{4}}\right)+\left(\frac{9.4537 T^{2}}{10^{7}}\right)-$ $\left(\frac{5.49031 T^{3}}{10^{10}}\right)+\left(\frac{7.9298 T^{4}}{10^{14}}\right)$

The pressure drop across the combustion chamber $\left(\Delta \mathrm{P}_{\mathrm{cc}}\right)$ is usually around $2 \%$ [21]. The turbine inlet pressure $\left(\mathrm{P}_{05}\right)$ can be calculated as:

$P_{05}=P_{04}\left(1-\Delta P_{c c}\right)$

where $P_{05}$ is the turbine entry level pressure, $P_{04}$ is the combustion chamber inlet pressure, and $\Delta P_{c c}$ is pressure drop across the combustion chamber.

The heat delivered by the combustion chamber is determined from energy balance:

$\dot{Q}_{\text {in }}=C_{p g}\left(T_{05}-T_{04}\right)$

Where $\mathrm{C}_{\mathrm{pg}}$ is the specific heat capacity of combustion products; the $\mathrm{C}_{\mathrm{pg}}$ in this work is considered to be a temperature variable function as [29]:

$c_{p g}(T)=0.991615+\left(\frac{6.99703 T}{10^{5}}\right)+\left(\frac{2.7129 T^{2}}{10^{7}}\right)-$ $\left(\frac{1.22442 T^{3}}{10^{10}}\right)$

The mass flow rate of fuel is computed as [20]:

$\dot{m}_{f}=\frac{\dot{Q}_{\text {in }}}{L H V \times \eta}$

where LHV is the lower heating value of the fuel (natural gas) and $\eta_{\text {com }}$ is combustor efficiency.
The exhaust gases temperature from the gas turbine is given as:

$T_{06}=T_{05}\left\{1-\eta_{T}\left[1-\left(\frac{P_{05}}{P_{06}}\right)^{\frac{1-\gamma g}{\gamma_{g}}}\right]\right\}$

where $\eta_{T}$ is the turbine isentropic efficiency and $P_{06}$ is the ambient pressure.

The turbine power is equal to:

$\dot{W}_{T}=\dot{m}_{g} c_{p g}\left(T_{05}-T_{06}\right)$

where $\dot{m}_{\mathrm{g}}$ is the mass flow rate of flue gas and it is given by

$\dot{m}_{g}=\dot{m}_{a}+\dot{m}_{f}$

The net power obtained from the gas turbine is given by:

$\dot{W}_{N e t}=\dot{W}_{T}-\dot{W}_{C}$

The specific fuel consumption (SFC) is determined by equation (14). The specific fuel consumption compares the ratio of the fuel used by an engine to a characteristic power such as the amount of power the engine produces. This is a very important economic criterion.

$S F C=\frac{3600 \cdot \dot{m}_{f}}{\dot{W}_{N e t}} \mathrm{~kg} / \mathrm{kWh}$

Heat rate (HR) of a gas turbine cycle is determined by:

$H R=S F C \times L H V$

The thermal efficiency of the gas turbine is calculated as:

$\eta_{t h}=\frac{\dot{W}_{N e t}}{\dot{m}_{f} \times L H V}$

\subsection{Thermodynamic Model of Gas Turbine Unit with Cooling System}

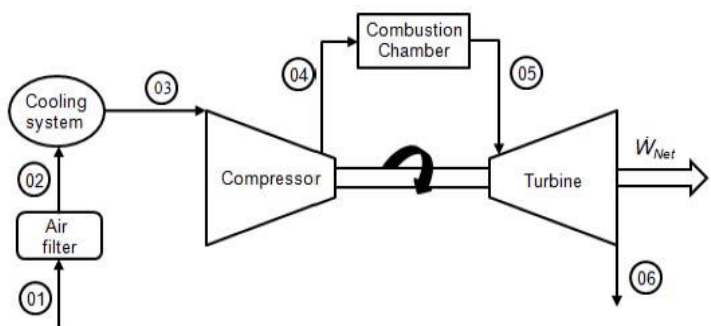

(0)

Figure 2 Schematic diagram of the gas turbine cycle with cooling system.

Figure 2 is a schematic diagram of a gas turbine cycle with cooling system. The gas turbine power plant consists of compressor, combustion chamber and turbine. In this study, the inlet air cooling technique proposed for analysis is evaporative cooling. The performance of the gas turbine will be evaluated with the proposed cooling technique and compared with values of the simple gas turbine.

In the evaporative cooler, water drains through the distribution pad into the media, by gravity action downward through it, and wets an enormous area of media surface contacted by air passing through the cooler. The dry air 
mixes with water becoming saturated where the Dry Bulb Temperature (DBT) of inlet air reaches initial Wet Bulb Temperature (WBT).

It is assumed that the relative humidity of outlet air from the cooler will not exceed $100 \%$ despite the inlet air condition. The humidifying efficiency is assumed to be $100 \%$. The gas turbine power plant models are developed on the following assumptions: (i) all components have adiabatic boundaries, (ii) plant performance at ISO conditions, (iii) the air and the combustion products have ideal characteristics, (iv) kinetic and potential components of energy are neglected, and (v) the ambient conditions of temperature and pressure are $25^{\circ} \mathrm{C}$ and 1.013 bar.

\subsubsection{Humidifier Model}

Cooling in hot and relatively dry climate can be accomplished by evaporative cooling [20]. This is because the cooling technique utilizes the latent heat of vaporization to cool ambient temperature from the dry temperature [21]. Evaporative cooling involves passing air across a spray of water or forcing air through a soaked pad that is kept replenished with water [22]. Owing to the low humidity of entering air, a part of the water injected evaporates. The energy required for evaporation is provided by the air stream, which undergoes a reduction in temperature. The following assumptions are made in the humidifier model.

- The relative humidity at the humidifier outlet is $95 \%$

- The pressure drop of air in the humidifier is $1 \%$ of the ambient air pressure.

The most common media type of evaporative coolers is a wetted honeycomb-like medium to maximize evaporative surface area and cooling potential. Figure 3 illustrates the principle of operation of evaporative cooler. According to Ibrahim et al [9], this cooling equipment is placed after the air filter system as shown in Figure 3. This type of arrangement protects the media from the dust and other airborne contaminants that would otherwise impinge upon it. Evaporative cooling involves heat and mass transfer, which occurs when water and the unsaturated air-water mixture of the incoming air are in contact [11]. This transfer is a function of the differences in temperatures and vapour pressures between the air and water. Heat and mass transfer are both operative in the evaporative cooler because the heat transfer from air to water evaporates water, and the water evaporating into the air constitutes mass transfer.

In evaporative cooling, sensible heat from the air is transferred to water, which becomes latent heat as the water evaporates. The water vapour becomes part of the air and carries the latent heat with it. The air dry-bulb temperature decreases because it gives up the sensible heat. The air wetbulb temperature is not affected by the absorption of latent heat in the water vapour because the water vapour enters the air at the air's wet-bulb temperature.

Theoretically, the incoming air and water in the evaporative cooler are considered as an isolated system due to no heat being added to or removed from the system. The process of exchanging the sensible heat of the air for latent heat of evaporation from water is adiabatic [23]. Such a system is used as a preferred solution in dry/desert climate, which can be expected to boost the gas turbine power by nearly $12 \%$. Meanwhile, for hot humid climates, the aircooling is limited to the wet bulb temperature and the capacity of the gas turbine generator may not be increased by more than 5 to $7 \%$ in best cases [24].

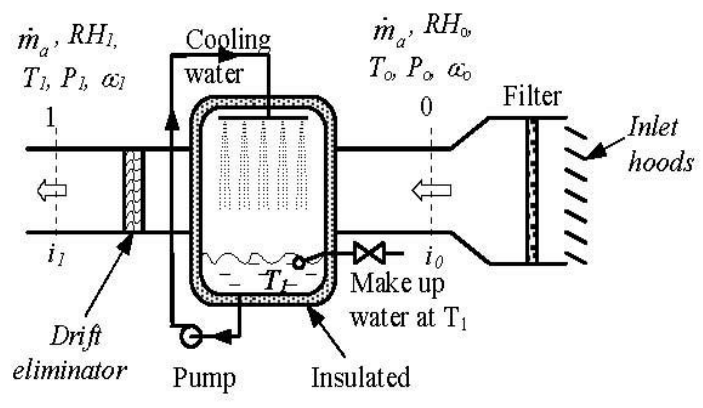

(a)

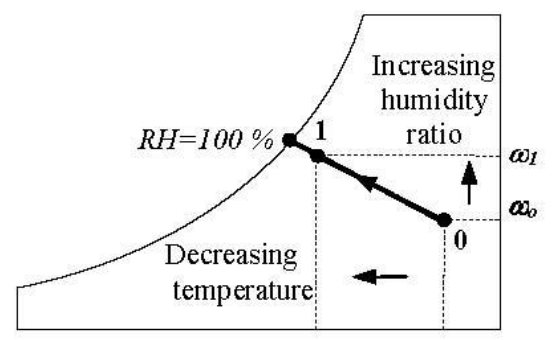

(b)

Figure 3: (a) Schematic of adiabatic evaporative cooler (b) Adiabatic saturation process on the psychometric chart: RH-Relative Humidity.

Applying the mass balance equation across the humidifier control volume boundary gives

$\omega_{a, e}=\omega_{a, i}+m_{w}$

where $\omega$ is the specific humidity and is calculated at a certain temperature as

$\omega=\frac{0.622 P_{v}}{P-P_{v}}$

where $P_{v=} \phi . P_{\text {sat }}$ is the partial pressure of vapour, $\emptyset$ is the relative humidity and $P_{\text {sat }}$ is the saturation pressure of air corresponding to the desired temperature.

The energy balance equation for the humidifier is given by:

$h_{a, e}=h_{a, i}+\left(\omega_{a, e}-\omega_{a, i}\right) h_{w}$

where $h_{a, e}$ and $h_{a, I}$ are the enthalpy of moist air at outlet and inlet of the air humidifier respectively and are calculated as follows

$h_{a, e}=C_{p, a, e} t_{a, e}+\left(2500+1.88 t_{a, e}\right) \omega_{a, e}$

$h_{a, i}=C_{p, a, i n} t_{a, i}+\left(2500+1.88 t_{a, i}\right) \omega_{a, i}$

$T_{a, e}=t_{a, e}+273$

The equations $(17-20)$ can be solved to determine the value of $\mathrm{T}_{\mathrm{a}, \mathrm{e}}, \omega_{\mathrm{a}, \mathrm{e}}$ and $\mathrm{m}_{\mathrm{w}}$. The inlet air temperature after the cooling process (Figure 3) can be calculated as:

$T_{03}=T b_{02}-\varepsilon .\left(T b_{02}-T w_{02}\right)$

where $\mathrm{Tb}_{02}$ is the dry-bulb temperature, $\mathrm{Tw}_{02}$ is the wetbulb temperature and $\varepsilon$ is the cooling effectiveness. 
The cooling load associated with the evaporative cooling system results in:

$\dot{Q}_{C L}=\dot{m}_{a} \cdot C_{p a}\left(T_{02}-T_{03}\right)$

where $\dot{m}_{\mathrm{a}}$ is the air mass flow rate and $\mathrm{C}_{\mathrm{pa}}$ is the specific heat of the dry air at constant pressure, determined as a function of the average temperature across the evaporative system.

The working fluid passing through the compressor is assumed to be an ideal mixture of air and water vapour. The total enthalpy of atmospheric air is given as [14]:

$h=h_{a}+\omega \times h_{v} \cong C_{p a} T_{a}+\omega h_{v}$

where $h_{a}$ is the enthalpy of dry air, and $h_{v}$ is the enthalpy of water vapour.

The enthalpy of water vapour can be evaluated by [25]:

$h_{v}=2501.3+1.8723 T_{j}$

where $j$ refers to state 04 or 05 .

The total temperature of the fluid leaving the compressor having an isentropic efficiency $\eta_{C}$ can be evaluated using ideal gas relation:

$T_{4 s}=T_{03}+\frac{T_{03}}{\eta_{C}}\left[r_{p}^{\frac{\gamma-1}{\gamma}}-1\right]$

where $r_{p}$ is the compression ratio and $\gamma$ the specific heat ratio. Similarly, the total temperature leaving the turbine having an isentropic efficiency $\eta_{\mathrm{T}}$ is given by:

$T_{6 s}=T_{05}-\eta_{T}\left(T_{05}-T_{06}\right)$

The total mass flow rate of humid air is given as:

$\dot{m}_{h a}=\dot{m}_{d a}+\omega \dot{m}_{d a}=(1+\omega) \dot{m}_{d a}$

where, $\dot{m}_{h a}$ and $\dot{m}_{d a}$ are mass flow rates of humid air and dry air respectively. The compressor work for humid air between states 03 and 04 is calculated from the mass flow rate and enthalpy change across the compressor:

$\dot{W}_{c}=\dot{m}_{a}(1+\omega) \times C_{p a}\left(T_{4 s}-T_{03}\right)+\omega\left(h_{4 s}-h_{03}\right)$

The power produced by the turbine due to expansion of hot gases is obtained as:

$\dot{W}_{T}=\dot{m}_{t} C_{p g}\left(T_{05}-T_{06}\right)+\omega\left(h_{05}-h_{06}\right)$

where

$\dot{m}_{t}=\dot{m}_{a}+\dot{m}_{v}+\dot{m}_{f}=\dot{m}_{a}(1+\omega+f)$

$f=\frac{\dot{m}_{f}}{\dot{m}_{a}}$

The net power obtained from the gas turbine is given as:

$\dot{W}_{n e t}=\dot{W}_{T}-\dot{W}_{C}$

The thermal efficiency of the gas turbine is given as: $\eta_{t h}=\frac{\dot{W}_{n e t}}{\dot{m}_{f} \times L H V}$

The specific fuel consumption of the gas turbine is computed by:

$S F C=\frac{3600 \times \dot{m}_{f}}{\dot{W}_{\text {net }}} \mathrm{kg} / \mathrm{kWh}$

\section{Results and Discussion}

The parameter influences in terms of ambient temperature, compression ratio and turbine inlet temperature on the performance of gas turbine cycle power plant are presented in this section. The effects of operation conditions on the network output, specific fuel consumption and efficiency are obtained by the energy-balance utilizing MATLAB10 software. In this study, a single shaft gas turbine is numerically simulated operating with natural gas. Table 1 shows the technical parameters for the selected gas turbine unit used to evaluate both the performance of the base-case (without cooling intake air) and evaporative inlet air cooling. A simple gas turbine was simulated employing the ISO conditions without cooling and varying ambient air temperature, turbine inlet temperature and compression ratio.

\subsection{Effect of Ambient Temperature}

Figures 4 - 6 show the effect of ambient temperature on the performance of both simple gas turbine and evaporative cooling inlet conditions. Figure 4 shows that the gas turbine thermal efficiency is affected by ambient temperature due to the change of air density and compressor work. A lower ambient temperature leads to a higher air density and a lower compressor work that in turn gives a higher gas turbine output power as shown in Figure 5.

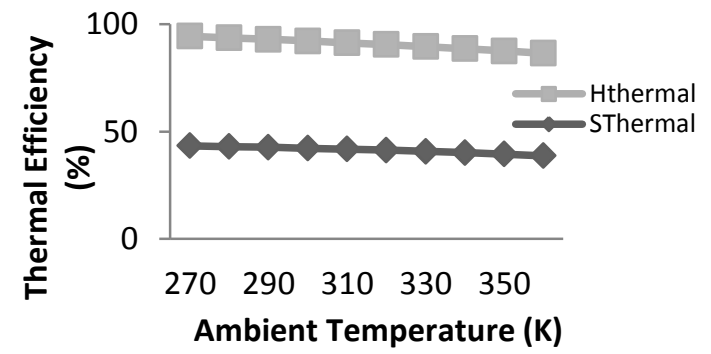

Figure 4: Effect of ambient temperature on gas turbine thermal efficiency; SThermal - simple gas turbine thermal efficiency, Hthermal -humidified gas turbine thermal efficiency.

It can be seen from Figure 4 that when the ambient temperature increases the thermal efficiency decreases. This is because, the air mass flow rate inlet to compressor increases with decrease of the ambient temperature. So, the fuel mass flow rate will increase, since air to fuel ratio is kept constant. The power increase is less than that of the inlet compressor air mass flow rate; therefore, the specific fuel consumption increases with the increase of ambient temperature (Figure 6). This occurs because of increased losses due to the increased amount of flue gases.

Both net power output and thermal efficiency of simple cycle and evaporative cooling inlet conditions decrease with increase in ambient temperature. Specific fuel consumption of gas turbine cycle increases with increase in ambient temperature. This result shows the importance of low intake air temperature on the gas turbine performance. 


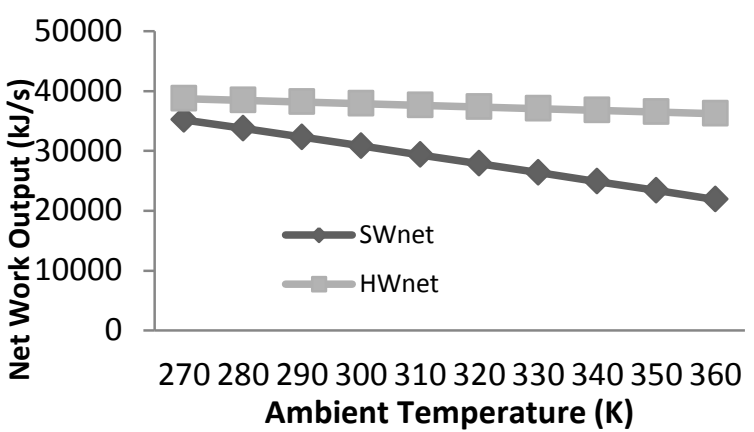

Figure 5: Effect of ambient temperature on Network output of gas turbine cycle; SWnet - simple gas turbine net work output, HWnet-Humidified gas turbine net work output.

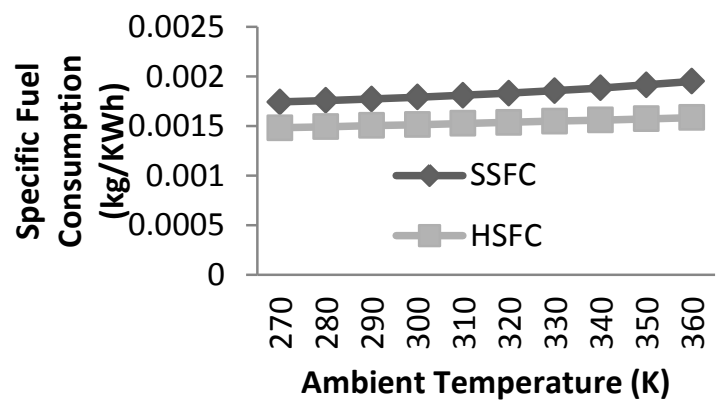

Figure 6: Effect of ambient temperature on specific fuel consumption of gas turbine cycle; SSFC - simple gas turbine specific fuel consumption, HSFC - humidified gas turbine specific fuel consumption.

From Figure 5 it can be seen that the net work output obtained is lower at ISO conditions, when the intake air is not cooled. This shows that the ambient dryness affects the gas turbine performance providing a higher power output level when the ambient relative humidity is lower. When the evaporative cooling technique is employed, the gas turbine thermal efficiency level is higher in comparison with the base-case as occurred for the power output results.

\subsection{Effect of Turbine inlet Temperature}

Figure 7 shows the relation between the thermal efficiency and turbine inlet temperatures of gas turbine power plants. Thermal efficiency has an ejective relationship with turbine inlet temperature, the efficiency increases when turbine inlet temperature increases, also the decrease in air to fuel ratio caused increased thermal efficiency. Thermal efficiency and net work output (Figure 8) increase with increase in turbine inlet temperature. But this increase is limited by metallurgical property of the turbine material. The specific fuel consumption (Figure 9) decreases with increase in turbine inlet temperature. This shows that gas turbine power plant performance can be improved by increasing the turbine inlet temperature.

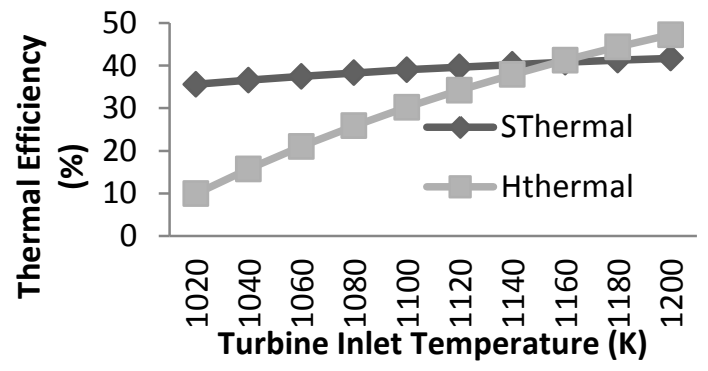

Figure 7: Effect of turbine inlet temperature on thermal efficiency of gas turbine plant.

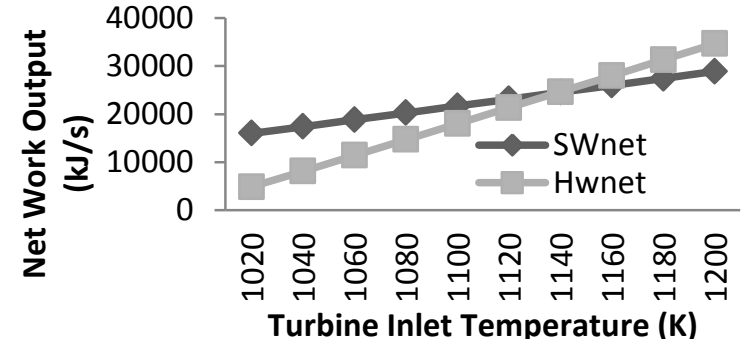

Figure 8: Effect of turbine inlet temperature on network output of gas turbine.

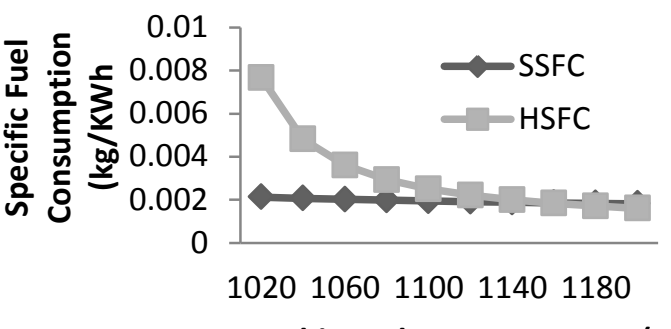

Turbine Inlet Temperature (K)

Figure 9: Effect of turbine inlet temperature on specific fuel consumption.

\section{Conclusions}

Operational parameters including the compression ratio, turbine inlet temperature and ambient temperature significantly influence the performance of a gas turbine power plant. The results are summarized as follows.

i) The thermal efficiency and net work output decrease while specific fuel consumption increases with increases in the ambient temperature.

ii) Increasing the turbine inlet temperature increases the output power and thermal efficiency while specific fuel consumption decreases.

iii) Evaporative cooling system improved the performance of a gas turbine power plant as the thermal efficiency and net work output are higher than that obtained from a simple gas turbine plant.

iv) This study shows the significant effect of incorporating air inlet cooling system to a simple gas turbine power plant in order to retrofit a gas turbine power plant in Nigeria.

v) The inlet air cooling system helps to reduce environmental pollution as the specific fuel consumption is less than that of a simple gas turbine plant.

\section{Nomenclature}

$C_{p} \quad$ Specific heat at constant pressure $\left[\mathrm{kJ} / \mathrm{kg}^{\circ} \mathrm{C}\right]$

LHV Lower Heating Value $[\mathrm{kJ} / \mathrm{kg}]$

$H \quad$ Specific enthalpy $[\mathrm{kJ} / \mathrm{kg}]$

$\mathrm{HR}$ Heat rate $[\mathrm{kJ} / \mathrm{kWh}]$

$\dot{m} \quad$ Mass flow rate $[\mathrm{kg} / \mathrm{s}]$

$P \quad$ Pressure[Pa]

$\Delta P \quad$ Pressure drop $[\mathrm{Pa}]$

$\dot{Q} \quad$ Heat transfer rate[kW]

$r_{p} \quad$ Compression pressure ratio[-]

$T$ Temperature [K ]

$T_{\mathrm{b}} \quad$ Dry bulb temperature[K]

$T_{\mathrm{w}} \quad$ Wet bulb temperature[K]

$\dot{W} \quad$ Power output[MW]

SFC Specific fuel consumption[kg/kWh]

$\varepsilon \quad$ Evaporative cooling effectiveness[-] 
Relative humidity[ -]

Specific heat ratio[-]

Efficiency[ -]

Specific humidity $\left[\mathrm{kg}_{\text {water }} / \mathrm{kg}_{\text {air }}\right]$

\section{Subscript}

$0 \quad$ Ambient air

01,02,03,04,05,06 Points denoted in Figures $1 \& 2$

a Air

C Compressor

da Dry air

g Flue gas

ha Humid air

in Inlet

$\mathrm{T}$ Turbine

th Thermal efficiency

w water

\section{References}

[1] F. G. Mahmood, D. D. Mahdi, A New Approach for Enhancing Performance of A Gas Turbine (Case Study: Khangiran Refinery), Appl. Energy, 86, 2750-2759, 2009.

[2] Büche, D, Multi-Objective Evolutionary Optimization of Gas Turbine Components, Unpublished (Doctoral Dissertation) Swiss Federal Institute of Technology, Zürich, 2003.

[3] T. K. Ibrahim, M. M. Rahman, A. N. Abdalla, Study on the effective parameter of gas turbine model with intercooled compression process, Scientific Research and Essays, 5, 3760-3770, 2010.

[4] Q. M. Jaber, J. O. Jaber, M. A. Khawaldah, Assessment of Power Augmentation from Gas Turbine Power Plants Using Different Inlet Air Cooling Systems, Jordan Journal of Mechanical and Industrial Engineering, 1, 7-15, 2007.

[5] F. I. Abam, I. U. Ugot and D. I. Igbong, Thermodynamic assessment of grid-based gas turbine power plants in Nigeria, J. Emerg. Trends Eng. Applied Sci., 2, 1026-1033, 2011.

[6] M. Farzaneh-Gord, M. Deymi-Dashteba, Approach for Enhancing Performance of a Gas Turbine (Case Study: Khangiran Refinery), Applied Energy, 86, 2750-2759, 2009.

[7] J. Bird, W. Grabe, Humidity effects on gas turbine performance, ASME Paper No 91-GT-329, 1991.

[8] A. A. El-Hadik, The impact of atmospheric conditions on gas turbine performance, J Eng Gas Turb Power, 112, 590-596, 1993.

[9] T. K. Ibrahim, M. M. Rahman, A. N. Abdalla, Improvement of gas turbine performance based on inlet air cooling systems: A technical review, International Journal of Physical Sciences, 6, 620-627, 2011.

[10] X. Shi, B. Agnew, D. Che, J. Gao, Performance enhancement of conventional combined cycle power plant by inlet air cooling, inter-cooling and LNG cold energy utilization, Applied Thermal Engineering 30, 2003-2010, 2010.

[11] R. Hosseini, A. Beshkani, M. Soltani, Performance improvement of gas turbines of Fars (Iran) combined cycle power plant by intake air cooling using a media evaporative cooler, Energy Conversion and Management 48, 1055-1064, 2007.

[12] M. Farzaneh-Gord, M. Deymi-Dashtebayaz, Effect of various inlet air cooling methods on gas turbine performance, Energy, 36, 1196-1205, 2011.

[13] I. Al-Tobi, Performance Enhancement of Gas Turbines by Inlet Air Cooling, International Conference on Communication, Computer and Power (ICCCP'09) Muscat, February 15-18: 165 - 170, 2009

[14] F. I. Abam, I. U. Ugot, D. I. Igbong, Performance Analysis and Components Irreversiblities of a (25 MW) Gas Turbine Power Plant Modeled with a Spray Cooler, American J. of Engineering and Applied Sciences 5, 35-41, 2012.

[15] R. S. Johanson, The Theory and Operation of Evaporative Coolers for Industrial Gas Turbine Installations, Gas Turbine and Aero-engine Congress and Exposition, June 5-9, Amsterdam, The Netherlands, Paper No. 88-GT-41, 1988.

[16] I. S. Ondryas, D. A. Wilson, M. Kawamoto, G.L. Haub, Options in Gas Turbine Power Augmentation Using Inlet Air Chilling, Engineering for Gas Turbine and Power, Transaction of the ASME, Vol. 113, 203$211,1991$.

[17] T. Johnke, M. Mast, Power boosters - technologies to enhance gas turbine power output on demand, Siemens Power J Online May (2002) www.siemenswestinghouse.com/download/pool/mast_ engl_3.pdf.

[18] M. Ameri, S. H. Hejazi, The study of capacity enhancement of the Chabahar gas turbine installation using an absorption chiller, Appl. Therm. Eng, 24, 5968, 2004.

[19] E. Kakaras, S. Doukelis, S. Karellas, Compressor intake-air cooling in gas turbine plants, Energy, 29, 2347-2358, 2004.

[20] P. Ewa, J. Szymon, M. Andrzej, Impact of inlet air cooling on gas turbine performance, Journal of Power Technologies, 92, 249-257, 2012.

[21] P. S. Ana Paula, R. A. Claudia, L. S. Edson, Comparison of Different Gas Turbine Inlet Air Cooling Methods, World Academy of Science, Engineering and Technology, 61, 40 -45, 2012.

[22] H. Kurt, Z. Recebli, E. Gredik, Performance analysis of open cycle gas turbines, International Journal of Energy Research, 33, 285-294, 2009.

[23] C. Yang, C. Yang, Z and R. Cai, Analytical Method Evaluation of Gas Turbine Inlet Air Cooling in Combined Cycle Power Plant, Applied Energy, 86, 848-856, 2009.

[24] G. M. Zaki, R. K. Jassim, M. M. Alhazmy, Energy, Exergy and Thermoeconomics Analysis of Water Chiller Cooler for Gas Turbines Intake Air Cooling, Smart Grid and Renewable Energy, 2, 190-205, 2012.

[25] M. Jonsson, J. Yan, Humidified gas turbines-a review of proposed and implemented cycles, Energy, 30, 1013$1078,2005$. 